Revista Destaques Acadêmicos, Lajeado, v. 11, n. 2, 2019. ISSN 2176-3070

DOI: http://dx.doi.org/10.22410/issn.2176-3070.v11i2a2019.2254

http://www.univates.br/revistas

\title{
OS LIMITES DOS NEGÓCIOS JURÍDICOS PROCESSUAIS ATÍPICOS NO NOVO CÓDIGO DE PROCESSO CIVIL ${ }^{1}$
}

\author{
Raphael Felipe de Omena Lima², Cayan Araujo Oliveira ${ }^{3}$
}

Resumo: Neste trabalho analisa-se a temática dos limites dos negócios jurídicos processuais atípicos. O trabalho está estruturado em três seções. A primeira destinase à apresentação do tema, às delimitações necessárias e às inquietações que levaram à produção deste trabalho; a segunda está relacionada à metodologia empregada; já a terceira desenvolve o cerne da pesquisa, enfrentando os objetivos propostos. O objeto da pesquisa é o estudo dos limites dos negócios jurídicos processuais atípicos. O estudo se deu por meio da aplicação do método de interpretação jurídica sistemático juntamente com o bibliográfico-documental. Quanto à natureza, a pesquisa possui o caráter teórico e prático. Durante a pesquisa apurou-se que existem limites à atuação das partes e que a atuação deve ser respaldada na boa-fé e no respeito ao contraditório, além de na obediência aos ditames da teoria geral do Direito, regulada pelo Código Civil. Tal obediência justifica-se porque a natureza dos negócios jurídicos segue a dos fatos jurídicos. Os negócios jurídicos processuais atípicos são manifestações autônomas de vontade externadas pelas partes, extrajudicial ou judicialmente, com o fim de estipular mudanças no procedimento para ajustá-lo às especificidades da causa e convencionar sobre seus ônus, poderes, faculdades e deveres processuais. O artigo 190 do CPC/2015 estabelece que o processo deve versar sobre direitos que admitam autocomposição e que as partes sejam plenamente capazes. Observam-se, no período anterior, os limites postos pelo próprio legislador à extensão da atuação da atipicidade. Identificou-se também que é assegurado o acesso à justiça e a possibilidade de negociação processual em contratos de adesão, desde que não sejam abusivos. Dessa forma, é possível determinar que há limitações no que diz respeito aos negócios jurídicos processuais atípicos.

Palavras-chave: Código de Processo Civil. Negócio Jurídico Processual Atípico. Limites.

1 Trabalho desenvolvido no âmbito do PROGRAMA SEMENTE DE INICIAÇÃO CIENTÍFICA - PSIC, do Centro Universitário Cesmac, selecionado com bolsa pelo próprio PSIC. Orientado pelo prof. Dr. Ricardo Schneider Rodrigues.

2 Acadêmico do Curso de Direito do Centro Universitário Cesmac (CESMAC), Bolsista na Procuradoria da Fazenda Nacional de Alagoas.

3 Acadêmico do Curso de Direito do Centro Universitário Cesmac (CESMAC), Bolsista no Ministério Público do Estado de Alagoas. 


\section{INTRODUÇÃO}

Os negócios jurídicos processuais remontam à pandectística alemã, que estudava a compilação de leis romanas (Corpus Iuris Civilis), organizada por ordem do imperador Justiniano (THEODORO JUNIOR et al., 2015, p. 257). Várias disposições permitiam o acordo entre as partes, como os pactos de exclusão de um grau de jurisdição, os de exclusão de competência e os de inversão do ônus da prova, entre outros (THEODORO JUNIOR et al., 2015, p. 257-258).

No aspecto do direito comparado, os negócios jurídicos processuais também são conhecidos e disciplinados de acordo com suas peculiaridades. $\mathrm{Na}$ Inglaterra, há o case management, em que o procedimento é estabelecido de acordo com o valor da causa e o grau de complexidade das questões fáticojurídico-probatórias, entre outros aspectos (THEODORO JUNIOR et al., 2015, p. 271). Na França, o Nouveau Códe de Procédure Civile também prevê o referido instituto; Dequeker destaca a importância de se instaurar um diálogo permanente entre os atores do processo de forma a propiciar a celeridade do procedimento (2005, p. 19-20 apud THEODORO JUNIOR et al., 2015, p. 274275).

Didier e Nogueira definem negócio jurídico como o fato jurídico voluntário cujo suporte fático confere ao sujeito o poder de escolher a categoria jurídica ou estabelecer, dentro dos limites fixados no próprio ordenamento jurídico, certas situações jurídicas processuais (APUD, DIDIER JR; BOMFIM, 2017, p. 106). Pode-se afirmar que "o acordo processual não visa solucionar o conflito, mas regulamentar, nos moldes desejados pelas partes, o próprio método de solução, isto é, o exercício da jurisdição" (ALMEIDA, 2014, p. 104).

Fundado no princípio da cooperação e tendo em vista a economia e a celeridade processuais, a cláusula geral de negociação processual do art. 190 do CPC/2015 faculta às partes a possibilidade de estipular mudanças no procedimento, a fim de ajustá-lo às especificidades da causa e convencionar sobre os seus ônus, poderes, faculdades e deveres processuais, antes ou durante o processo.

Embora fosse instituto bastante conhecido no âmbito do Direito Civil, havia muita discussão quanto à existência dos negócios jurídicos no âmbito do Código Processo Civil de 1973 (CPC/73), sendo aceita apenas por parcela da doutrina (DIDIER JR.; BOMFIM, 2017, p. 106-107). No Direito Administrativo e no Direito Penal, tais convenções são reconhecidas em alguns casos, como na colaboração premiada em demandas de improbidade administrativa e nas técnicas de justiça penal consensual, como a transação penal (art. 76, Lei $\mathrm{n}^{\circ}$ 9.099/1995) e a suspensão condicional do processo penal (art. 89, Lei $\mathrm{n}^{0}$ 9.099/1995) (DIDIER JR.; BOMFIM, 2017, p. 117; CABRAL, 2015, p. 547).

A partir do novo Código de Processo Civil (CPC/2015), não há mais dúvidas quanto à existência das convenções processuais na seara do processo 
civil, em especial pela previsão de seu art. 190; este passou a estabelecer uma cláusula geral de negócios jurídicos processuais atípicos, além dos diversos negócios processuais típicos previstos no Código, tais como o calendário processual (art. 191), a delimitação consensual das questões de fato e de direito relevantes (art. 357, § $2^{\circ}$ ) e a convenção sobre o ônus da prova (art. $373, \S 3^{\circ}$ ).

Câmara (2017, p. 116) aduz que a partir do art. 190, nas causas que versam sobre "direitos que admitam autocomposição", partes capazes podem "estipular mudanças no procedimento para ajustá-lo às especificidades da causa e convencionar sobre os seus ônus, poderes, faculdades e deveres processuais, antes ou durante o processo". Fica claro, com a leitura do dispositivo, que apenas partes capazes podem celebrar negócios processuais, não sendo válida sua celebração por incapazes, ainda que representados ou assistidos.

Contrapondo-se à assertiva posta, Didier entende que as partes devem ser capazes processualmente para que seja possível a existência da validade do negócio jurídico processual atípico. Por exemplo, um menor, logo, incapaz, em regra, não pode celebrar um negócio jurídico processual, contudo, caso o menor esteja sendo representado corretamente, não há razões para que não celebre o negócio (2016, p. 70).

Por se tratar de instituto novo, é de extrema importância apontar os limites para a celebração de tais negócios jurídicos. A partir do enunciado expresso do Código, exigem-se como requisitos apenas a capacidade plena das partes e que o processo verse sobre direitos que admitam autocomposição (art. 190, caput). Almeida sustenta que o ato, além de dispositivo, deve ser bilateral e manifestamente expresso (ALMEIDA, 2014, p. 168). Ademais, previu-se o controle judicial em caso de nulidade, inserção abusiva em contrato de adesão ou manifesta situação de vulnerabilidade (art. 190, parágrafo único).

Leonardo Carneiro da Cunha destaca que o grande desafio da doutrina será justamente identificar os limites para os negócios jurídicos processuais (2014, p. 30-31). O autor entende que não seriam cabíveis convenções relacionadas à aceitação de prova ilícita, à fundamentação de decisões judiciais ou para impor sigilo ou segredo de justiça ao processo (CUNHA, 2014, p. 30-31). Já Fredie Didier Jr. admite a celebração de acordo para decisão por equidade ou baseada em Direito estrangeiro ou consuetudinário (2015, p. 381-382).

Em sentido contrário, há o Enunciado $\mathrm{n}^{\circ} 36$, aprovado em evento realizado pela Escola Nacional de Formação e Aperfeiçoamento de Magistrados (ENFAM), por aproximadamente 500 magistrados, no sentido de que o CPC / 15 não admitiria a celebração de negócios que estipulassem o julgamento do conflito com base em lei diversa da nacional vigente (2015).

A pesquisa justifica-se diante do elevado número de demandas atualmente submetidas ao crivo do Poder Judiciário e da sua demora em ofertar uma resposta. Conforme dados apontados pelo Conselho Nacional de Justiça, ao final de 2015 havia no Brasil aproximadamente 74 milhões de processos em 
trâmite (2016, p. 383); o tempo médio para a execução na Justiça Estadual era de nove anos (2016, p. 383).

Diante desse cenário, as partes tendem a buscar alternativas que abreviem o desfecho de seus processos. Um caminho aberto pelo CPC/15 consiste justamente na cláusula geral do art. 190 do CPC/15, por permitir que as próprias partes, independentemente de autorização judicial, promovam alterações no procedimento que possam contribuir para uma solução rápida e efetiva do caso concreto. Daí a necessidade de aprofundar o estudo dos limites das alterações que poderão ser realizadas pelas partes ao celebrarem os negócios jurídicos processuais atípicos.

Neste trabalho pretendeu-se enfrentar a seguinte questão: quais os limites expressos e implícitos à celebração, pelas partes, dos negócios jurídicos processuais atípicos fundamentados no art. 190 do Código de Processo Civil? A hipótese de partida conduz ao caminho de que além dos limites previstos expressamente no Código, outros também poderiam ser extraídos do ordenamento jurídico, tais como os princípios da boa-fé e da cooperação, além do dever de proteção dos direitos fundamentais (CABRAL, 2016, p. 249-340).

Para tanto, foram definidos como objetivos específicos: comparar, a partir da análise da legislação e da doutrina, as mudanças havidas na transição entre os regimes do $\mathrm{CPC} / 73$, em relação ao $\mathrm{CPC} / 15$, com destaque para as principais características do novo Código e enfoque no regime jurídico dos negócios jurídicos processuais; indicar, a partir do exame da legislação processual e civilista, além da respectiva doutrina, a natureza jurídica dos negócios jurídicos em geral e dos negócios jurídicos processuais, com o intuito de identificar o seu regime jurídico, em especial quanto à submissão ou não às regras gerais pertinentes aos negócios jurídicos disciplinadas no Código Civil; traçar as diferenças entre os negócios jurídicos típicos e atípicos no CPC /15, de acordo com o tratamento conferido pela legislação processual e pela doutrina, para estabelecer as principais características de cada espécie, delimitando, assim, o objeto do trabalho (= negócios jurídicos processuais atípicos).

Também compõem os objetivos deste trabalho elencar os requisitos para a celebração dos negócios jurídicos processuais atípicos do art. 190 do CPC/15, identificando aqueles expressamente indicados no novo Código e eventuais outros implícitos, previstos em outras normas, como, v.g., no Código Civil ou na Constituição da República, a partir do exame do ordenamento jurídico e da doutrina; pesquisar, no âmbito da jurisprudência do Superior Tribunal de Justiça e do Tribunal de Justiça do Estado de Alagoas, se já há julgados relativos aos negócios jurídicos processuais atípicos do $\mathrm{CPC} / 15$, com o fim de descrever quais seriam os limites já identificados concretamente pelos órgãos jurisdicionais e estabelecer os limites expressos e implícitos para a celebração de negócios jurídicos processuais atípicos fundados no novo Código de Processo Civil, para delimitar os contornos da moldura jurídica dentro da qual é possível celebrar convenções válidas. 
Por fim, no tocante à metodologia, utilizou-se o método monográfico, através do estudo minucioso do que vem a ser o negócio jurídico processual, quais os requisitos positivos e negativos a que eles devem atender, bem como a diferença entre os negócios jurídicos processuais típicos e atípicos. Destacase, ainda, que a pesquisa possui o caráter teórico e prático, possuindo como alicerce a compreensão da doutrina especializada acerca do tema.

\section{O CPC/73 E O CPC/15: DIVERGÊNCIA ENTRE PUBLICISMO E PRIVATISMO E O SURGIMENTO DE UM NOVO MODELO}

Compreende-se que as mudanças do CPC/73, em relação ao CPC/2015, observam-se a partir da divergência entre o publicismo e o privatismo. $\mathrm{O}$ Código de Processo Civil de 73 é visto por meio da aludida ótica publicista, e o CPC/15 surge a fim de extinguir este paradigma, utilizando o modelo cooperativo.

O regramento publicista caracteriza-se por possuir aspectos autoritários na formulação dos procedimentos, uma vez que o publicismo nega a existência da vontade das partes e, ainda, proporciona maiores poderes ao magistrado no desenrolar material e formal do processo. O privatismo, por sua vez, é, em síntese, uma forma de observar o processo a partir de um modelo emanado de liberdade, no qual é possível averiguar a diminuição da intervenção estatal e o trilhar do caminho privado.

De acordo com Barreiros, o privatismo processual é observado como "coisa das partes", pois tal modelo propulsiona domínio do procedimento às partes, devido à autonomia privada gerada por este (2017, p. 97).

A partir desta premissa, a grande problemática, senão a maior de todas, dava-se na tentativa de mesclar o caráter público com a adaptabilidade do procedimento privatista. Segundo Lorena Miranda Santos Barreiros, surge o modelo cooperativo como solução da relação dicotômica que, além de confirmar a superação dos modelos antecedentes, adota a ideia de equilíbrio entre o privatismo e o publicismo por meio da valorização do autorregramento, onde os sujeitos processuais agem coordenadamente para alcançar uma decisão justa do litígio, em andamento razoável (2017, p. 106 e 107).

\subsection{Das mudanças entre o CPC/1973 e o CPC/2015}

De acordo com Barreiros, com a chegada do CPC/73, os efeitos dos atos das partes são produzidos imediatamente, ou seja, a eficácia dos atos de disposição das partes não está, em regra, a depender da permissão do magistrado, conforme o caput do art. 158: "os atos das partes, consistentes em declarações unilaterais ou bilaterais de vontade, produzem imediatamente a constituição, a modificação ou a extinção de direitos processuais". Porém, apesar da possibilidade de negócio jurídico processual típico (eleição de foro, convenção sobre o ônus da prova, adiamento consensual da audiência, 
suspensão convencional do processo...), o dispositivo ainda é observado a partir da ótica publicista, devido à prevalência do órgão jurisdicional em relação às partes e à carência emanada do caput do art. 158 no tocante à matéria procedimental, autocomposição e ao negócio jurídico processual atípico. Pelo menos é assim que a doutrina o encarava (2017, p. 110 e 111).

De mais a mais, o Código de Processo Civil de 2015 propicia grande importância à autonomia da vontade das partes, considerando até mesmo o art. 190 como uma cláusula geral de atipicidade da negociação processual. Malgrado haja maior concordância atualmente, Barreiros observa que o negócio jurídico processual fora aquele que sofreu menor aceitação em relação às outras teorias dos fatos jurídicos processuais, pois o publicismo possuía fortes raízes e, portanto, não era possível enxergar o negócio processual (interesse privado) que se desprendesse da ideia normativa ou de dependência judicial (2017, p. 128 e 129).

Assim, uma das características destoantes que distingue o Código de Processo Civil de 2015 do de 1973 é a amplitude concedida aos negócios processuais atípicos, sendo, de uma forma geral, mais reconhecido, seja por sua cláusula geral, seja por sua aceitação, ou pela adequação do modelo cooperativo.

\section{O NEGÓCIO JURÍDICO PROCESSUAL}

Para Nogueira, a definição de negócio processual é dada com fundamento na ideia de um fato jurídico emanado de vontade, que é incidido em seu suporte fático a partir da previsão em determinada regra processual e irá conferir ao indivíduo o efeito do negócio processual, desde que sua vontade selecione o que a norma prevê (2011, p. 137).

\subsection{A distinção entre o negócio jurídico processual típico e atípico}

Compreende-se que o negócio jurídico processual típico é caracterizado como tal por possuir prévia definição e regulamentação própria, assim como aduz Barreiros em sua obra, alegando que o negócio processual típico indica uma categoria já delimitada pelo ordenamento jurídico por meio de sua regulamentação e prévia definição.

Em relação aos negócios processuais atípicos, a ótica incide sobre a formulação de limites no ordenamento jurídico, pois não há de se falar em prévia definição, a julgar a falta de regulamentação normativa específica. Assim, a atipicidade se enquadra, por função, no alcance de certas situações jurídicas processuais ou até mesmo na alteração do procedimento por meio da permissividade da cláusula geral do CPC/15, art. 190 (2017, p. 140).

Cabe salientar que numa perspectiva doutrinária dogmática, os negócios jurídicos processuais atípicos decorrem dos fatos jurídicos em sentido amplo, os quais se subdividem em fatos jurídicos stricto sensu e atos jurídicos lato sensu, 
conferindo o último o embasamento teórico para a subsistência dos negócios jurídicos, que, como já foi dito, podem ser típicos e atípicos.

Conforme aduz Cabral (2016, p. 44-45), “a sistemática existente na teoria do Direito para o estudo dos atos jurídicos em geral pode ser transposta, em grande medida, para o Direito processual, já que os atos do processo são, inegavelmente, espécies de ato jurídico".

\subsection{Dos requisitos do negócio jurídico processual}

É possível elencar requisitos implícitos ao Código de Processo Civil, mas que regulam também o que está disposto na cláusula geral de atipicidade. Quanto aos requisitos de validade encarados pelas partes litigantes, Fredie Didier acredita que, "para serem válidos, os negócios processuais devem: (a) ser celebrados por pessoas capazes; (b) possuir objeto lícito; (c) observar a forma prevista ou não proibida por lei" (DIDIER, 2016, p. 70). Esses requisitos estão previstos no Código Civil, assim como há outros decorrentes de outras fontes normativas, a exemplo do acordo de leniência e do acordo de colaboração premiada.

Ademais, faz-se necessário versar sobre os requisitos expressos localizados no art. 190 do Código de Processo Civil de 2015. O processo deve versar sobre direitos que admitam autocomposição, e as partes devem ser plenamente capazes de estipular mudanças no procedimento, a fim de adequálo às especificidades da causa e convencionar os atos processuais antes ou durante o processo.

\section{OS LIMITES DOS NEGÓCIOS JURÍDICOS PROCESSUAIS ATÍPICOS}

Quanto aos limites expressos e implícitos para a celebração de negócios jurídicos processuais atípicos, Cabral aduz:

[...] entretanto, o tão só fato de tratar-se de uma cláusula geral não a torna hermética ou incontrolável. É possível sindicar racionalmente a concretização das cláusulas gerais, seja por razões formais (v.g., motivação insuficiente, art. $489 \S 1^{\circ}$, VI do CPC/2015), seja por razões de fundo (compreensão errônea de seu conteúdo ou aplicação equivocada das consequências possíveis [...] (CABRAL, 2016, p. 330).

O presente trabalho não tem o objetivo de exaurir o tema, sendo possível trazer, além dos já mencionados limites previstos no Código Civil, os também previstos na Constituição Federal, representados por normas cogentes. São eles: o princípio do acesso à justiça (art. $5^{\circ}, \mathrm{XXXV}$, da $\mathrm{CR} / 88$ ); do devido processo legal (art. $5^{\circ}$, LIV, da CR/88); do juiz natural (art. $5^{\circ}$, XXXVII e LIII, da CR/88); da ampla defesa e do contraditório (art. $5^{\circ}, \mathrm{LV}$, da CR/88). 


\subsection{A doutrina: as duas correntes dos limites do negócio jurídico processual atípico}

Em relação à doutrina, os limites dos negócios jurídicos processuais se observam através de duas correntes. De acordo com Barreiros, a primeira parte da doutrina consagra limites genéricos, e a segunda parte descreve, por meio de diretrizes que servem de "auxiliares metódicos", a especificidade dos limites (2017, p. 253).

\subsubsection{A corrente que constitui limites através de indicantes gerais}

Os autores que têm os limitadores genéricos como suficientes acreditam que, majoritariamente, os negócios jurídicos processuais atípicos não podem violar as normas cogentes.

Conforme Barreiros, Giorgio de Nova (2008, p. 68, apud BARREIROS, 2017, p. 253) considera que estabelecer os limites dos negócios processuais atípicos é dificultoso, haja vista uma possível violação de normas cogentes.

Remo Caponi (2008, p. 108, apud BARREIROS, 2017, p. 253) visualiza o negócio processual atípico como uma fonte munida de capacidade, a ponto de vincular o juiz a tal, desde que não exista violação às normas cogentes.

José Carlos Barbosa Moreira (1984, p. 185, apud BARREIROS, 2017, p. 254) expressa um critério de distinção entre normas cogentes e dispositivas com base na análise da doutrina alemã. Entende que os negócios jurídicos processuais que prejudicassem as normas dispositivas seriam admitidos, entretanto as convenções processuais que violassem as normas cogentes seriam negadas. Moreira observa que o critério abordado não possui grande utilidade, dada a dificuldade para diferenciar as normas dispositivas e as normas cogentes.

Leonardo Greco (2008, p. 293, apud BARREIROS, 2017, p. 255) ressalta a necessidade de respeitar a ordem pública processual, conferindo proteção aos direitos fundamentais e ao devido processo legal.

Barreiros aponta outros autores que abordam esses limitadores genéricos, como Marcelo Pacheco Machado, Flávio Luiz Yarshel e Diogo Assumpção (2017, p. 254-255).

\subsubsection{A corrente que estabelece limites por meio de diretrizes}

A outra parte da doutrina enfoca a matéria mediante diretrizes que servem como "auxiliares metódicos". Estes visam propiciar ao juiz uma solução justa, nos moldes da especificidade da causa, possuindo como justificativa existencial a falta de regulamentação por parte dos negócios jurídicos atípicos.

Conforme Barreiros, Leonardo Carneiro da Cunha (2015, p. 58-59, apud BARREIROS, 2017, p. 257) entende que é de enorme importância que os 
acordos processuais acatem as garantias fundamentais do processo, existindo imprescindivelmente um controle de validade. Elabora, para tanto, quatro diretrizes: a) em contrato de adesão, a convenção processual será permitida quando o contrato não for abusivo, tampouco inválido, ou se dele vier a instaurar-se a vulnerabilidade de um dos convenentes; b) o negócio jurídico processual não pode violar as normas cogentes; c) o acordo processual, quando se tratar de direito indisponível, não pode afastar sua regra protetiva; d) o acordo processual também não poderá dispor sobre matéria de reserva de lei.

Já Fredie Didier Junior (2016, p. 391-394, apud BARREIROS, 2017, p. 256-257) elabora oito diretrizes: a) in dubio pro libertate: quando existir dúvida a respeito da ilicitude, deve-se aceitar o negócio processual, salvo na existência de interpretação restritiva condutora; b) negociação somente em autocomposição, haja vista a possível alteração da solução do objeto litigioso; c) a aplicabilidade dos negócios processuais segue a regra material sobre injuridicidade do objeto do negócio jurídico; d) a obediência da lei ao tipificar os negócios processuais típicos, impedindo o negócio processual atípico como configuração burladora, isto é, quando existir norma regulamentadora da matéria, esta deve ser seguida; e) a impossibilidade de negócio processual sobre matéria de reserva legal; f) o objeto do negócio processual abrangente de possível afastamento de norma cogente protecionista de direito indisponível é inadmissível; g) o negócio processual, contanto que não haja abusividade, é permitido em contratos de adesão; h) a possibilidade de negócio processual atípico, adsorvido pelas partes, consagrador de sanções e deveres distintos do rol legal.

Antônio do Passo Cabral (2016, p. 316-329, apud BARREIROS, 2017, p. 257) também estabelece diretrizes correlacionadas ao controle de licitude do objeto da convenção processual. Para esse autor, o objeto da convenção não deverá versar sobre matéria de reserva legal; a cooperação e a boa-fé deverão ser respeitadas; deverá existir proteção à situação de vulnerabilidade, ocasionando equilíbrio da relação das partes; e, por último, a impossibilidade de a convenção processual ocasionar externalidades, onerando economicamente o Poder Judiciário ou terceiros.

Cabral (2016, p. 331, apud BARREIROS, 2017, p. 257) assevera que como exteriorização do direito à liberdade, a autonomia da vontade deve observar limites internos ou imanentes, devido ao status de direito fundamental, além da possibilidade de limites externos, em razão do possível atrito desse exercício de liberdade com outros direitos fundamentais. Ainda, Barreiros destaca que Murilo Teixeira Avelino também se encaixa no segmento doutrinário que utiliza diretrizes para a análise dos limites objetivos de validade dos negócios processuais atípicos (2017, p. 258-259).

Diante das duas correntes doutrinárias que estabelecem limites para as convenções processuais atípicas, a corrente que utiliza auxiliares metódicos remete a um panorama adequado ao abordar os limites de forma específica. As diretrizes abordadas por Didier, Cunha e Cabral possuem maior objetividade 
acerca dos limites das convenções processuais atípicas, caracterizando apurada completude acerca da matéria, haja vista a necessidade de objetividade do assunto, inclusive por se tratar de restrições à autonomia da vontade das partes que, desta forma, abrange o direito fundamental à liberdade.

Concorda-se com o pensamento de Barreiros ao expressar que a ponderação se dá devido ao conflito do direito à liberdade com outro direito fundamental perturbado pelo ajuste da convenção. A partir dessa ótica, fazse necessário demandar valoração ponderativa, bem como a fundamentação adequada por parte do juiz, na hipótese de invalidação da convenção processual, ressalvando apenas que só será possível a invalidez desde que haja prejuízo. Obedece-se, por conseguinte, ao regime de invalidades processuais (BARREIROS, 2017, p. 260-261).

\section{PESQUISA POR JURISPRUDÊNCIA: QUAIS SERIAM OS LIMITES JÁ IDENTIFICADOS CONCRETAMENTE PELOS ÓRGÃOS JURISDICIONAIS?}

Aqui será analisada a demanda postulada no TJ-RS, uma apelação cível em razão do artigo 190 do CPC e sua atipicidade, a fim de impugnar o julgamento por inobservância a acordo estabelecido na audiência de conciliação.

A análise se deu através do voto do relator, Des. Paulo Sergio Scarparo, o qual, nesse caso em questão, foi o voto acolhido pela $16^{\mathrm{a}}$ Câmara Cível da Comarca de Santo Ângelo. Em síntese, foi possível notar que o Juízo de primeiro grau, de fato, não observou o acordo ora estabelecido, um acordo válido com base na atipicidade do artigo 190 do CPC. Dessa forma, maculou o procedimento, gerando um prejuízo irreparável para a ré, S \& K PRODUTOS PARA SAÚDE LTDA., em que pese ela ter se tornado revel durante todo o decorrer do processo. Diante dos fatos, a Turma acima citada deu provimento, por unanimidade, a fim de desconstituir a sentença e retornar os autos ao Juízo de primeiro grau, para que seja possível sanar o vício.

Cabe mencionar que a pesquisa até o presente momento não localizou nenhum julgado no âmbito do TJ/AL e do STJ. Tratando-se de um instituto que ainda está sendo amplamente difundido na doutrina com o fim de estabelecer paradigmas, é cedo para se falar em jurisprudência, pois existem tão somente as primeiras decisões a respeito do tema, que podem servir de apoio nas demandas iniciais, mas não há uma consolidação, haja vista o curto período transcorrido desde a vigência do novo CPC.

\section{CONSIDERAÇÕES FINAIS}

O artigo 190 do atual CPC abre uma nova possibilidade acerca do instituto dos negócios jurídicos processuais, possibilidade esta que em sua própria redação literal já sofre algumas limitações: as partes devem ser capazes, o objeto deve ser lícito, e os processos devem admitir a autocomposição. 
Vistos esses limites impostos à sua extensão, as perguntas que pairavam a respeito eram: até onde se daria a aplicabilidade desses acordos de vontades das partes? Até onde as partes poderiam convencionar? As partes poderiam limitar os poderes do magistrado?

Passados pouco mais de três anos da publicação do Código de Processo Civil de 2015 e dois anos de sua vigência, coube à jurisprudência julgar os casos, formando novos entendimentos; e coube à doutrina estudar o tema, buscando soluções para essa e as demais perguntas que passaram a surgir a respeito. $\mathrm{O}$ estudo do tema ainda não se esgotou, mas até aqui muito já se produziu. Nomes como Freddie Didier Jr. e Humberto Theodoro Junior deram uma parcela de contribuição bem significativa na busca do conhecimento do instituto e de repostas para as dúvidas existentes.

Por ora, à primeira vista, já se poderia constatar que as partes não poderiam convencionar sobre todos os ônus, poderes, faculdades e deveres processuais que lhes pertencem numa relação jurídica. Este trabalho demonstrou que a liberdade é dada para celebrar um acordo com enfoque nos princípios do autorregramento da vontade das partes e da cooperação processual, uma vez que sofre limitações do princípio do devido processo legal e do contraditório.

Verificou-se, ainda, que o campo de abrangência dado às partes pelo novo Código de Processo Civil não é tão volátil quanto parece, haja vista o trabalho desempenhado pela doutrina e aqui já exposto, estabelecendo alguns limites à atuação das partes. É possível citar, por exemplo, o entendimento de Didier, para quem seria inadmissível o objeto do negócio processual afastar uma norma cogente protecionista de um direito indisponível.

Sabe-se que os fatos preexistem às normas e que os fatos jurídicos preexistem aos negócios jurídicos. Desta maneira, infere-se que os negócios jurídicos processuais são regulados também pela teoria geral do direito, ou seja, atendendo às regras do direito material, no tocante ao preenchimento dos campos da existência, da validade e da eficácia. Além das limitações previstas na redação do artigo 190 do CPC, os negócios jurídicos processuais também sofrem outras restrições advindas de leis diversas, como, por exemplo, o Código Civil e a Constituição Federal.

Para se chegar aos limites impostos aos negócios jurídicos processuais atípicos, foi necessário entender o que são tais negócios e de onde surgiram. Desse modo, o estudo partiu do histórico com base no direito comparado. A discussão nos séculos XIX e XX girava em torno de publicismo versus privatismo. Já no final do século XX, o estudo voltou-se para os problemas então existentes no Judiciário, o alto grau de complexidade das causas, a morosidade exacerbada e o alto custo para se ter acesso ao Judiciário.

Com o intuito de sanar essas mazelas é que na França e na Inglaterra surgiram os primeiros modelos de processo cooperativo, deixando de lado a contenda entre publicismo e privatismo. Novos institutos como a conciliação e 
a mediação passaram a ter um maior destaque, e com isso o procedimento foi se moldando, surgindo então os contrats de procédure. Tais mudanças culminaram na elaboração do Código de Processo Civil de 2015.

Entende-se que o objetivo da pesquisa foi alcançado, pois há muitos limites impostos à atuação das partes no processo, dentre eles a impossibilidade de se convencionar no processo de modo a tornar uma das partes excessivamente vulnerável, bem como não merece prosperar os acordos de vontade contrários aos princípios basilares do $\mathrm{CPC} / 2015$, dentre eles são eles o da cooperação e o da boa-fé processual. Ademais, no próprio art. 190, é possível perceber os requisitos como limites legalmente constituídos, assim como a elaboração de diretrizes por parte da doutrina que auxiliam na constatação desses limites - por exemplo, a não admissão de negócio jurídico processual atípico como forma burladora da tipologia legal existente, no caso, as convenções processuais típicas.

Cumpre destacar a inter-relação do direito processual civil com o direito constitucional, cuja autonomia da vontade é consagrada como exteriorização do direito à liberdade, logo, suscetível à colisão com outros direitos fundamentais. Consequentemente, o órgão jurisdicional deverá ser responsável por interpretar e ponderar se, nessa situação, a convenção processual atípica deve ser mantida ou não.

Posto isso, o novo instituto atende às expectativas de se criar um processo mais cooperativo, haja vista o princípio da cooperação, assim como o do autorregramento da vontade das partes.

\section{REFERÊNCIAS}

ALMEIDA, Diogo Assumpção Rezende de. Das convenções Processuais no Processo Civil. 2014. 239 f. Tese (Doutorado) - Universidade do Estado do Rio de Janeiro Faculdade de Direito, 2014.

BARREIROS, Lorena Miranda Santos. Convenções Processuais e Poder Público. Salvador: Juspodivm, 2017.

BRASIL. Código Civil. Organização de Sílvio de Salvo Venosa. São Paulo: Atlas, 2003.

BRASIL. Constituição (1988). Constituição da República Federativa do Brasil. Brasília, DF: Senado Federal: Centro Gráfico, 1988, 292 p.

CABRAL, Antonio do Passo. Convenções Processuais. Salvador: Juspodivm, 2016.

CAMARA, Alexandre Freitas. O Novo Processo Civil Brasileiro. 3. ed. São Paulo: Atlas, 2017. 
CONSELHO NACIONAL DE JUSTIÇA. Justiça em Números 2016: ano-base 2015. Brasília: CNJ, 2016. Disponível em: <www.cnj.jus.br/files/conteudo/ arquivo/2016/10/b8f46be3dbbff344931a933579915488.pdf>. Acesso em: 17 jan. 2017.

CUNHA, Leonardo Carneiro da. Negócios jurídicos processuais no processo civil brasileiro. In: CONGRESSO PERU-BRASIL DE DIREITO PROCESSUAL, 1., 2014, Lima. Disponível em: <https://www.academia.edu/10270224/Neg\%C3\%B3cios_ jur\%C3\%ADdicos_processuais_no_processo_civil_brasileiro $>$. Acesso em: 28 jul. 2016.

DIDIER JR., Fredie; BOMFIM, Daniela Santos. A colaboração premiada como negócio jurídico processual atípico nas demandas de improbidade administrativa. A\&C Revista de Direito Administrativo \& Constitucional, Belo Horizonte, ano 17, n. 67, p. 105-120, jan./mar. 2017.

DIDIER JR., Fredie. Negócios Jurídicos Processuais Atípicos no Código de Processo Civil de 2015. Revista Brasileira de Advocacia, ano 1, v. 1, p. 59-84, abr./jun. 2016.

ESCOLA NACIONAL DE FORMAÇÃO E APERFEIÇOAMENTO DE MAGISTRADOS. Enunciados aprovados. In: Seminário - O Poder Judiciário e o novo Código de Processo Civil, 26 a 28 ago. 2015. Disponível em <http:/ / www. enfam.jus.br/2015/09/enfam-divulga-62-enunciados-sobre-a-aplicacao-do-novocpc/>. Acesso em: 16 mai. 2017.

FINCATO, Denise. A pesquisa jurídica sem mistérios: do projeto de pesquisa à banca. Porto Alegre: Sapiens, 2014.

THEODORO JUNIOR, Humberto et al. Novo CPC: fundamentos e sistematização. São Paulo: Forense, 2015.

TJ-RS. APELAÇÃO CÍVEL: No 70075492462. Relator: Des. Paulo Sergio Scarparo. DJ 26/10/2017. JusBrasil, 2018. Disponível em: https:/ / tj-rs.jusbrasil.com.br/ jurisprudencia/516772765/apelacao-civel-ac-70075492462-rs/inteiro-teor-516772786. Acesso em: 1 ago. 2018. 